\title{
Einladung zur Einreichung wissenschaftlicher Abstracts
}

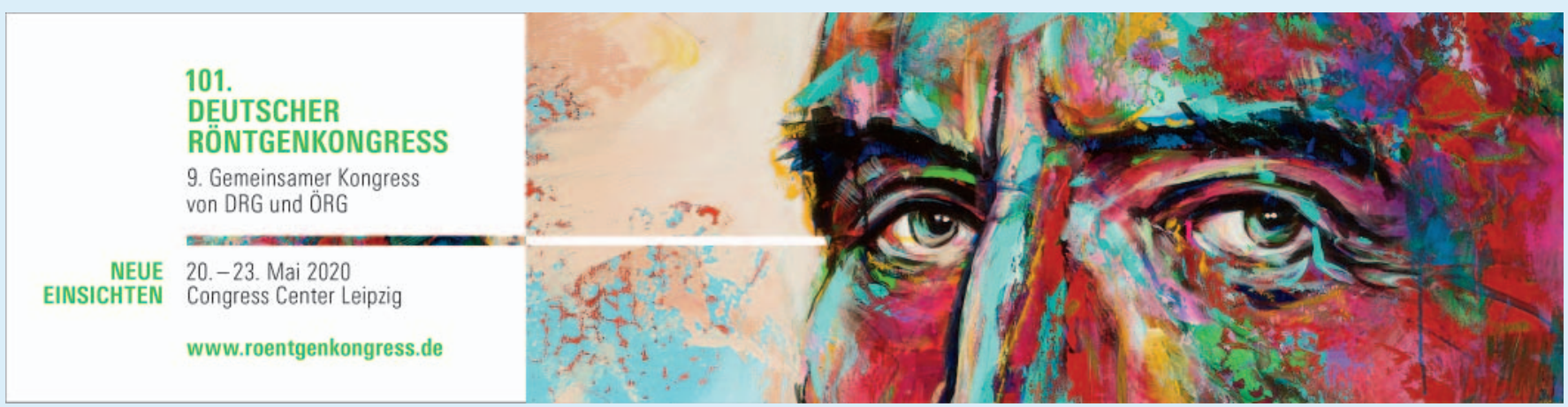

Seien Sie aktiv beim 101. Deutschen Röntgenkongress dabei! Ab sofort können Sie Ihre Abstracts für wissenschaftliche Vorträge oder Poster zu Wissenschafts- und Fortbildungsthemen einschließlich interessanter Kasuistiken (case reports) einreichen. Bitte reichen Sie Ihre Beiträge ausschließlich online über Ihren Kongress-Account unter www.roentgenkongress.de ein. Die Frist läuft bis zum 4. November 2019, 23.59 Uhr.

Nach einer Bewertung Ihres Abstracts erhalten Sie voraussichtlich im Dezember 2019 eine Information an Ihrem Abstract, ob Sie mit Ihrem Beitrag auf dem RöKo 2020 präsent sein können. Konkrete Präsentationstermine werden bis Ende Januar 2020 festgelegt sein.

\section{Jetzt e-Poster-Abstracts einreichen!}

Ebenfalls online über www.roentgenkongress. de können Sie ein Abstract für Ihr e-Poster einreichen. Ausgewählte Poster werden von den
Autorinnen und Autoren persönlich in täglich stattfindenden Poster-Sessions an einer Poster-Station im RöntgenFORUM (Halle 2) auf dem 101. RöKo präsentiert.

Die besten Poster werden mit einem DRGPoster-Preis prämiert und anschließend in conrad, der interaktiven Lernplattform der Deutschen Röntgengesellschaft, veröffentlicht.

Werden Sie mit Ihrem Beitrag Teil der DRGWissensgemeinschaft!

\section{Ihr MTRA-Poster auf dem RöKo}

Auch alle MTRA sind wieder herzlich eingeladen, ihre Abstracts zum RöKo 2020 für eine MTRA-Posterausstellung für Poster (Wissenschaft) und Poster (Fortbildung) einzureichen.

\section{Portal zur Hotelbuchung}

Die Leipziger Messe reserviert für die Teilnehmer des Röntgenkongresses umfangreiche Zimmerkontingente in zahlreichen Hotels in und um Leipzig. Suchen Sie bereits heute das passende Hotel, und buchen Sie Ihr Zimmer für den 101. RöKo! Sie haben die Möglichkeit, Ihre Reservierung über das Online-Buchungsportal der Messe Leipzig vorzunehmen - ab Anfang September ist es freigeschaltet. Den Link hierzu finden Sie unter www.roentgenkongress.de. Alle hier angebotenen Zimmer werden ohne Aufschläge an Sie weitergereicht.

Gern berät Sie das Team auch telefonisch bei Ihrer Hotelauswahl, beantwortet Ihre Fragen und unterstützt Sie, falls Sie besondere Wünsche haben. (Mo.-Fr. 9:00-17:00 Uhr).

Außerhalb dieser Zeit werden Ihre Anfragen per E-Mail entgegenkommen.

Hotel-Reservation Team

Tel. + $49341678-8725$

Fax: + $49341678-8722$

hotelreservation-roeko@leipziger-messe.de 